\title{
Knowledgebases: A Management Context and Development Determinants
}

\author{
Mieczyslaw L. Owoc \\ Wroclaw University of Economics, Wroclaw, Poland \\ Mieczyslaw.Owoc@ae.wroc.pl
}

\begin{abstract}
Contemporary computers give huge possibilities for processing different structures of data e.g. multimedia data types and very unconstrained in construction - object types. Moreover these different structures are processed using methods called intelligent. Knowledgebases (a specific sort of intelligent systems), as a consequence of variety of solutions, belong ambiguous terms. Principally, applications with a stored knowledgebase and a reasoning mechanism - to stress its structural components - are termed knowledgebases.

Directions of the research concerning knowledgebases and expressing their peculiar characteristics (coming from the main message of scientific formation in the past) are presented in this paper. The starting point of the paper is observed impact of management processes on intelligent systems and vice versa. Managerial context (including classical, behavioural, quantitative, integrating contemporary and future management approaches) of knowledgebases became the ground to draft development of applications of this sort framework. Taking into account research on knowledgebases, a set of knowledgebase development determinants is discussed.
\end{abstract}

Keywords : knowledgebase, knowledge management, intelligent system, management supporting, knowledge workers

\section{Introduction}

Contemporary computers give huge possibilities for processing different structures of data e.g. multimedia data types and very unconstrained in construction - object types. Moreover these structures are processed often and often using methods called intelligent. This is a domain of applications that utilising artificial intelligence technology, taking form of knowledge-based systems.

Knowledge-based systems, as a consequence of variety of solutions, belong to a group of ambiguous terms. Principally, applications with a stored knowledgebase and a reasoning mechanism - to stress its structural components - are termed knowledgebases. The endeavours in this area were so important that since long time many reports evaluating state of achievement and intentions connected with disciplines of artificial intelligence and their applications have been prepared (for example the report published in 70's - Lightill, 1971). Directions of research concerning knowledgebases and expressing their peculiar

Material published as part of these proceedings, either on-line or in print, is copyrighted by Informing Science. Permission to make digital or paper copy of part or all of these works for personal or classroom use is granted without fee provided that the copies are not made or distributed for profit or commercial advantage AND that copies 1) bear this notice in full and 2) give the full citation on the first page. It is permissible to abstract these works so long as credit is given. To copy in all other cases or to republish or to post on a server or to redistribute to lists requires specific permission from the publisher at Publisher@InformingScience.org characteristics (coming from the main message of scientific formation in the past) are presented in this paper. Such a context of knowledgebase development became the ground to discuss determinants of the development itself. The paper is enriched version of the previous work of the author (see: Owoc, 2001). 


\section{Management and Supporting Tools}

Management, as one of the main areas of applying computer science technologies, makes up a demanding challenge. The level of supporting classical functions connected with management changes, the more and more approaches to expectations of decisive makers. To make it clearer we can distinguish classes of supporting tools at the different levels of expectation of decisive subjects. Table 1 presents basic approaches to management with their characteristics expressing different aspects of functioning management supporting tools.

\begin{tabular}{|c|c|c|c|}
\hline \multirow[b]{2}{*}{ Approach } & \multicolumn{3}{|c|}{ Characteristics } \\
\hline & $\begin{array}{l}\text { Management's es- } \\
\text { sence }\end{array}$ & $\begin{array}{l}\text { Knowledge util- } \\
\text { ised }\end{array}$ & Supporting tools \\
\hline Classical & Functional analysis & Procedural & Transaction systems \\
\hline Behavioural & $\begin{array}{l}\text { Motivation of be- } \\
\text { haviour }\end{array}$ & Heuristic & Management information systems \\
\hline Quantitative & Models building & Declarative & Decision support systems \\
\hline Integrating & $\begin{array}{l}\text { Co-operation of } \\
\text { components }\end{array}$ & Structural & $\begin{array}{l}\text { Integrated management information } \\
\text { systems }\end{array}$ \\
\hline Contemporary & $\begin{array}{l}\text { Desired features } \\
\text { creating }\end{array}$ & $\begin{array}{l}\text { Meta- } \\
\text { knowledge }\end{array}$ & Knowledge-based systems \\
\hline Future & $\begin{array}{l}\text { Globalisation of } \\
\text { solutions }\end{array}$ & Distributed & Open knowledgebase systems \\
\hline
\end{tabular}

Figure 1. Evolution of approaches to management and relevant supporting tools Source: Own elaboration based on characteristics: Aldag and Stearns, 1987 and Griffin, 1993.

For every identified approach core of management, decisional needs representing the specific knowledge type as well as a class of software is pointed out. Types of knowledge include its differentiation in a common sense (see: Durkin, 1994, for example) and embrace knowledge representation forma lisms: procedural, heuristic etc. Supporting tools denote information system classes starting from transactionoriented systems up to advanced knowledge-based packages.

Classical approaches contain so-called "scientific management" represented by F. Taylor and "administrative management" created by H. Fayol (see Griffin, 1993). The issue both of them were to indicate key processes, managerial roles and skills -that are also now considered as actual. The classical approach is underlined as rather limited, that was addressed for stable and simple organisation and not making up the main management trend interest. Fayol's indication of 14 rules of effective management and especially emerging functions that compose described process - must be always taken into consideration in development or selection of management supporting tools. Therefore, describing destination or indicating the users of computer supporting solutions - we refer to canon of functions introduced by Fayol. Applications that have "grown up" on that approach we can define as transaction systems. They 
support management on the level of chosen functions, therefore tasks taking into account refers to frontline clerks. First of all, there are many events recorded and treated as independent transaction. Knowledge (or rather important information in such applications) can be described as procedural because it concerns information arrangements and their interpretation stressing necessary activities. Usually such sort of knowledge is described as procedural.

The centre of research in the behavioural approach becomes the behaviour of workers in an organisational context. In fact, it means taking into consideration largely understood interpersonal relations or problems of personnel motivation. The main representatives are E. Mayo, A. Maslow and D. McGregor (see: Griffin, 1993). Referring to the tools support, this way of creating management seems to be very distant from the typical software, however every management information system "touches" the described approach indirectly. As for more real examples of program tools addressed to behavioural approaches, we can name the systems explaining context the way of decision taking, stressing essential managerial factors. These systems are addressed to chosen management subjects, aimed at supplying individual, adequate to situation of decisive, selected information. The closest to this approach is a class defined as systems of informing managers. The character of knowledge (or rather necessary information) concerns solving problems in an individualised way, stem from gained experiences. That all let us define it as heuristic knowledge.

Quantitative approach concerning management contributed significantly to development of software packages utilised by modern managers. Mathematical models, studied in different areas of this approach, require supporting tools and consequently requires usage of computers in a more advanced way. Quantitative management theory and operational management - as the main symptoms of quantitative outlookwere built according to the problems of productive companies resulting in such techniques as linear programming, queue theory or simulation. Quantitative approach requiring access to transaction files, made up fundaments of successive developed informing managers systems in order to find completed solutions is typical for decision supporting systems. Supporting tools adequate to these approaches significantly service of such decisive models. Each of built models requires determining relationship between categories and variables essential for projected solution. Simplifying, knowledge expressed in this way we can define as declarative. It does not mean narrowing to statistical solutions; acceptable variants of interpretation of this relationship make that we have to deal with flexible models.

Integrating approach in more completed way outlines necessity of the global outlook to management. The concepts of system approach to different problems of organisation functioning, discovering synergetic effects, situational or universal outlook are respected in largely understood modern manager's equipment. At this moment we can say about full symbiosis of managerial, executive and informing systems as an essential instrument taking part in exchanging and transforming data into information and finally onto knowledge. We can name management supporting tools characteristic for described approach as integrated systems. Highly correlated effective programs create such systems, which contain highly structured information about component correlation. Therefore knowledge existing in such environments can be named structural.

Contemporary approaches propose taking into consideration solutions characteristic for effective American and Japanese enterprises - theory "Z" by Ouchi (Ouchi, 1981) - and they accent perfectionism as a form of action - Peters and Waterman, 1982. The list of essential features of management for modern firms is formulated in both approaches. These desired characteristics apply to interior company's arrangement (for example concern for workers) as well as its contact with its environment (customer service, for instance). This concept of management requires not only selective access to information but it is also necessary to remember informational structures with the possibility of their automatic interpretation, e.g. knowledge. That is indisputably domain of practical solutions utilising artificial intelligence denoting knowledge-based systems. There are used different types of knowledge depending on aims of tools supporting, with tendency of integrating few of above mentioned. It is suitable for meta- 
knowledge that allows generating solution-requiring interpretation of a situation of a company. The other goals can embrace: necessary corrective activities, diagnosis setting, indicating the source of failure - engaging suitable fragments of domain knowledge in any system, mostly supporting modern managers (compare: Taffinder, 1995).

Future proposals should be reactions to contemporary challenges. They include the proposals of solutions concerning globalisation of running business, problems of structure of employment (including unemployment) or still actual ethical and social responsibility. First of these challenges - globalisation requires supporting tools such as computer web-net or utilising of Internet. Future organisations should have a characteristic (still not yet very common) of self-learning (compare: Hesselbein, Goldsmith and Beckhard, 1996). It is possible to reach these goals only in a case of some specific classes of system with knowledgebases. We can assume that using local knowledgebases will be ineffective, therefore the co-operation between these systems and environment is necessary (open systems with knowledgebases). We must add necessity of distributing in case of contemporary required domain knowledge and superior to it meta knowledge. As a result new problems appear that are located in an area of relatively new subdiscipline so-called knowledge management, including concepts of knowledge society and knowledge economy (Drucker, 1968).

Summarising this short outlook of approaches to management and classes of supporting tools we can state that computer science means have developed also as a consequence of interactions in a domain of applying and transforming methods. Independently to form and efficacy of supporting, the assumptions concerning their destination were formulated in a similar way.

The matter was to provide the information first (and then knowledge), useful in a decision taking process or performing routine tasks composing management. From a moment, this supporting gets a special meaning, because of programming solutions where the processes of humans' thinking is imitated- it is called intelligence programming. We name here characteristics essential for such qualification like adapting to new situations, ability to learn- extending accessible knowledge, awareness of limitation. In addition possibility of solving certain problems or communication using "pseudo-natural" language can extend the defined framework.

We have to be aware that knowledge in case of management has quite troublesome characteristics: big fluctuation, uncertainty or incompleteness. It contributes in a significant way to development of certain disciplines of artificial intelligence, and consequently generating new research approaches.

\section{Research on Knowledgebases}

The background of knowledgebase development can be confronted with research directions of practical artificial intelligence applications. It should be stressed the boundary between so-called conve ntional software and software containing "intelligent" elements disappear more and more. This is very natural way of supplying computer programs with help functions that can be applied in different contexts, for example. This means knowledge "coded" in such applications has more universal understanding, not limited to particular cases. Let us inspect more obvious research of knowledgebases, stressing its managerial context.

The first challenge is to accept heterogeneous knowledge sources and its consequences. Knowledge, applied in decision-making processes principally in unstable conditions, comes from many sources in order to be completed. Knowledgebase openness on unlimited entries becomes a stimulator to development of more and more effective knowledge acquisition techniques. Knowledgebases, created in such a way, are supplied by outputs of transactional systems or simply are generated. Many sub-problems can be formulated: how to fit different knowledge representation formalisms or how to verify and validate hybrid knowledge representations (Vermesan and Coenen (eds.),1999). 
The most important problem to be solved in the nearest future is standardisation of knowledge representation. There are good examples in databases, where SQL became a standard language of definition and access to relational and recently object databases. UML plays the similar role in the whole system development life cycle. The basic difficulties of knowledge representation "unifying" arise from differentiation of knowledge sources and traditional independence of approaches to knowledge formalisation. This problem is very urgent to solve when the specific parts of knowledge have to be verified (its completeness or consistency for example). The translation of particular knowledge pieces to common formalism can be acceptable solution.

The next research topic refers to processes of creation and utilisation of knowledge rationale. More general - this is one of the crucial functions of knowledge management comprising of knowledge accumulation, sharing and application. In fact, knowledgebases are ready for use knowledge applications; therefore their role in the other phases of knowledge management has to be analysed. In particular, machine learning included to intelligent systems can be effective way of system adaptation.

Very close to the stated above is problem of knowledge effectiveness in various conditions. Some fragments of knowledge can be very dynamical, so certain alerting system supplied in knowledge management systems is very urgent. A simplified solution can be observing of knowledgebase reliability across the time (lower values of expertise reliability can be essential indicator of knowledge modification necessity).

The last area of research concerns communication aspects. This is very obvious expectation to build interface assuring natural language processing. Both input and output phases should be supported with more "human" dialog with knowledge systems (especially explanation options). Using multimedia in different phases of knowledge utilisation is the must.

The research presented in this section is typical for knowledge management endeavours (see: Mertins Heisig and Vorbeck, 2001 or Probst, Rauba and Romhardt, 2002). Some of them are of current interest. The need of knowledge management toolkits development have been regarded by scientists as well by knowledge workers (see: Tiwana, 2002). It seems to be very urgent to define general assumptions and guidelines for wide understood applications rooted in artificial intelligence.

\section{Knowledgebase Development Determinants}

The research areas presented in the previous section seem to be useful background for regarding knowledgebase development. In other words the mentioned issues can fruit some kind of principles that are essential for intelligent system development. This section comprises set of rules determining this process.

First of all, different knowledge sources have to be accepted in created knowledgebases. This "openness" on knowledgebase environments allows for more accurate knowledge representation. In reality this problem is solved in databases by gateways (specialised modules "transforming" original data sets onto models accepted in the particular database management system). Analogous solution can be introduced for knowledgebases despite of more complicated nature of knowledge structures.

Second, independence of knowledge sources creates better conditions for assuring knowledge reliability and confidence. This rule enforces in some way the first one and makes easier to keep knowledge granularity at the requested level. Every piece of knowledge can be stored separately retaining an "owner" stamp. As a consequence, one can identify knowledge sources applying knowledge validation procedures (see: Mach and Owoc, 2001).

Third, knowledge items incorporated into knowledgebase ought to be ranked. The matter is to denote some kind of knowledge likelihood in the chosen contexts. The particular facts or rules existing in a 
knowledgebase can be treated in different manners because of its uncertain evidence. This problem can be solved using fuzzy logic and inexact reasoning approach.

Knowledgebase tools should provide knowledge engineers mechanisms supporting knowledge structuring. Often and often there is a strong need to store so-called deep knowledge. There are many and various references in such sort of knowledge and all of them should be included in order to generate proper expertise. This is typical case for knowledgebases supporting managerial processes. Big number of components with dynamic interrelationships such domain knowledge require the pointed out mechanisms.

The last rule concerns incorporating of machine learning techniques in knowledgebases. This property is critical for all adaptable systems. The reasons are evident - to keep knowledgebase up-to-date automatic updating mechanisms have to be available in such intelligent systems. Management application area is such sort of systems therefore machine learning options are obligatory.

The proposed rules seem to be important for the entire knowledgebase development process as well as for its environment. Basically, the set has been directly rooted in the current research (see: Kautz, 2001 or Marwick, 2003). However the presented concepts can evolve in several directions. One of them is that proposed set rules could be extended by principles referring machine-reasoning module. The second one could be expressed as necessity of implementation of at least two strategies of reasoning. The others can concern communication with a knowledgebase via natural language as the must for applications support managers.

\section{Conclusion}

Intelligent systems can be developed in several directions including impact and expectations of the management side. In the paper some interactions between management and supporting intelligent tools have been stressed. This is common known more of the specified problems are not solved yet. Some guidelines referring knowledgebases development have been formulated. Early results indicate that the proposed set of principles formulates initial frames for endeavours aimed at knowledgebases quality.

\section{References}

Aldag R., J., Stearns T.M (1987). Management. South-Western Publishing Co. Cincinnati.

Drucker P. (1968). The Age of Discontinuity. Guidelines to our Changing Society. Harper Colophon Books, New York.

Durkin J. (1994). Expert Systems: Design and Development. Prentice Hall, Englewood Cliffs.

Griffin R., W. (1993). Management. Houghton Miffin Company.

Hesselbein F., Goldsmith M., Beckhard R. (1997). Organization of the Future. Jossey-Bass Inc.

Kautz K. (2001). Using IT to Support Knowledge Management-A Survey - Based Study of a Large, Global Consulting Company. Proceedings of the 2001 Informing Science Conference 2001 in Kraków, Poland.

Lightill J. (1972). Artificial Intelligence: A General Survey. Scientific Research Council of Britain, Cambridge University .

Mach M.A., Owoc M.L. (2001). Validation as the Integrated Part of a Knowledge Management Process. Proceedings of the 2001 Informing Science Conference 2001 in Kraków, Poland.

Marwick A.D. (2003). Knowledge Management Technology. Retrieved March 10, 2003 from http://www.research.ibm.com.journal/sj/404/marwick.html

Mertins K, Heisig P, Vorbeck J. (eds.) (2001). Knowledge Management. Best Practice in Europe. Springer-Verlag, Berlin.

Ouchi W. (1981). How American Business Can Meet the Japanese Challenge. Addison-Wesley, Reading Mass.

Owoc M.L. (2001). Bazy wiedzy - konteksty zarzadzania i przyszlosc. Materialy konferencyjne "Zarzadzanie i informatyka na poczatku XXI wieku". Prace Naukowe AE Wroclaw nr 898, Wydawnictwo AE, Wroclaw 2001. [Knowledgebases- 
Management Context and Future. Conference Proceedings: Management and Computer Science in the beginning of XXI century. Research Papers No. 898 of Wroclaw University of Economics, Wroclaw 2001] (in Polish).

Peters T.J., Waterman R.H. Jr. (1982). In Search of Excellence. Harper \& Row, New York.

Probst G., Raub S., Romhardt K. (2002). Managing Knowledge. Building Blocks for Success. John Wiley \& Sons, Ltd., Chichester.

Taffinder P. (1995). The New Leaders. Achieving Corporate Transformation through Dynamic Leadership. Kogan Page Ltd., London.

Tiwana A. (2002). The Knowledge Management Toolkit: Practical Techniques for Building a Knowledge Management System. Prentice-Hall Inc. Upper Saddle River.

Vermesan, A., Coenen, F. (eds.) (1999). Validation and Verification of Knowledge Based Systems: Theory, Tools and Practice. Kluwer Academic Publishers, Boston.

\section{Biography}

Owoc Mieczyslaw L., Ph.D. Eng. is a lecturer in the Faculty of Management and Computer Science Wroclaw University of Economics, Poland. Dr Owoc has authored almost 100 publications mostly oriented on databases and intelligent systems topics. In recent years he has been engaged in the international projects: "Knowledge Acquisition and Intelligent Distributed Learning in Resolving Managerial Issues" with Belgium and "Machine Learning 2000" with Sweden and Latvia. His current research is in modern information technologies including distance learning and knowledge management with focus on knowledge acquisition and validation. 